\title{
Glucose homeostasis in rats treated with 4-vinylcyclohexene diepoxide is not worsened by dexamethasone treatment
}

\author{
Francielle Garghetti Battiston ${ }^{a}$, Cristiane dos Santos ${ }^{\mathrm{a}}$, Amanda Marreiro Barbosa ${ }^{\mathrm{a}}$, \\ Sibele Sehnem ${ }^{\mathrm{a}}$, Ellen Cristina Rivas Leonel ${ }^{\mathrm{b}}$, Sebastião Roberto Tabogab ${ }^{\mathrm{b}}$, \\ Janete A. Anselmo-Francic ${ }^{\mathrm{C}}$, Fernanda Barbosa Lima ${ }^{\mathrm{a}}$, Alex Rafacho ${ }^{\mathrm{a}, *}$ \\ a Department of Physiological Sciences and Multicenter Graduate Program in Physiological Sciences, Center of Biological Sciences, Federal University of Santa \\ Catarina-UFSC, Florianópolis, Brazil \\ ${ }^{\mathbf{b}}$ Department of Biology, Institute of Biosciences, Letters and Exact Sciences, Univ. Estadual Paulista-IBILCE/UNESP, São José do Rio Preto, SP, Brazil \\ ${ }^{\mathrm{c}}$ Department of Morphology, Center of Biological Sciences, School of Dentistry of Ribeirão Preto, São Paulo University-USP, Ribeirão Preto, SP, Brazil
}

\section{A R T I C L E I N F O}

Article history:

Received 23 May 2016

Received in revised form 31 May 2016

Accepted 1 June 2016

Available online 3 June 2016

\section{Keywords:}

Aging

Female

Metabolism

Ovarian failure

Senescence

Steroid hormones

\begin{abstract}
A B S T R A C T
4-vinilcyclohexene diepoxide (4-VCD) causes premature ovarian failure and may result in estrogen deficiency, characterizing the transition to estropause in rodents (equivalent to menopause in women). Estropause/menopause is associated with metabolic derangements such as glucose intolerance and insulin resistance. Glucocorticoids (GCs) are known to exert diabetogenic effects. Thus, we aimed to investigate whether rats with premature ovarian failure are more prone to the diabetogenic effects of GC. For this, immature female rats received daily injections of 4-VCD [160 mg/kg body weight (b.w.), intraperitoneally (i.p.)] for 15 consecutive days, whereas control rats received vehicle. After 168 days of the completion of 4-VCD administration, rats were divided into 4 groups: CTL-received daily injections of saline $(1 \mathrm{~mL} / \mathrm{kg}, b . w .$, i.p. $)$ for 5 days; DEX-received daily injections of dexamethasone $(1 \mathrm{mg} / \mathrm{kg}, b . w ., i$. p.) for 5 days; VCD - treated as CTL group; VCD + DEX-treated as DEX group. Experiments and euthanasia occurred one day after the last dexamethasone injection.

4 -VCD-treated rats exhibited ovary hypotrophy and reduced number of preantral follicles $(p<0.05)$. Premature ovarian failure had no impact on the body weight gain or food intake, but both were reduced by the effects of dexamethasone. The increase in blood glucose, plasma insulin and triacylglycerol levels as well as the reduction in insulin sensitivity caused by dexamethasone treatment was not exacerbated in the VCD + DEX group of rats. Premature ovarian failure did change neither the hepatic content of glycogen and triacylglycerol nor the glycerol release from perigonadal adipose tissue. Glucose intolerance was observed in the VCD group after an ipGTT $(p<0.05)$, but not after an oral glucose challenge. Glucose intolerance and compensatory pancreatic $\beta$-cell mass caused by GC were not modified by ovarian failure in the VCD + DEX group. We conclude that reduced ovarian function has no major implications on the diabetogenic effects promoted by GC treatment, indicating that other factors related to aging may make rats more vulnerable to GC side effects on glucose metabolism.
\end{abstract}

() 2016 Elsevier Ltd. All rights reserved.
Abbreviations: b.w., body weight; CTL, rats treated with saline; DEX, rats treated with dexamethasone; ELISA, enzyme-linked immunosorbent assay; FSH, folliclestimulating hormone; HOMA, homeostatic model assessment; i.p., intraperitoneal; ipGTT, intraperitoneal glucose tolerance test; LDL, low density lipoprotein; GC, glucocorticoid; OVX, ovariectomy; RIA, radioimmunoassay; s.c., subcutaneous; TyG, triacylglycerol and glucose index; 4-VCD, 4-vinylcyclohexene diepoxide; VCD, rats treated with 4-VCD; VCD + DEX, rats treated with 4-VCD and dexamethasone; VLDL, very-low density lipoprotein.

* Corresponding author at: Departmento de Ciências Fisiológicas, Centro de Ciências Biológicas, Universidade Federal de Santa Catarina-UFSC, 88040-900, Florianópolis, Brazil.

E-mail addresses: alex.rafacho@ufsc.br, alex.rafacho@ufsc.br, http://www.lidoc.ccb.ufsc.br (A. Rafacho).

\section{Introduction}

During natural aging many physiological functions may be impaired, e.g., changes of neurologic, metabolic, and cardiovascular magnitudes. Almost all species have a lifespan that does not surpass their reproductive years [1]. This is not the case in women, who experience a reproductive senescence around the fifth decade of life as a consequence of a depletion of their finite pool of ovarian follicles, a process known as atresia [1]. This midlife transition state that culminates with reproductive senescence in women is termed perimenopause and can last 5-8 years on average until 
menopause occurs (cessation of menstrual period) [2]. About one third of every woman's life is spent in the post-reproductive stage, since the average life expectancy at birth for both sexes worldwide is 71 years [3]. The impacts of perimenopause and menopause on health and diseases are unequivocally an important matter for investigation, which continuously supports the actions of the health-related professionals dealing with elderly patients.

Different animal models have been considered in scientific researches to mimic some aspects of women reproductive senescence, without the heterogeneous variations found in humans (e.g., genetic characteristics, diet, age, parity, socioeconomic status, and environmental exposures) [1]. Different from human females, rodents present an estrous cycle rather than a menstrual cycle and the estrous cycle lasts $4-5$ days. Also, rodents do not exhibit menstruation, but have the uterine lining reabsorbed [4]. Rats and mice commonly experience irregular estrous cycle around 9-12 months of age, a condition termed estropause [1]. Three main laboratory models define the preclinical models for evaluation of reproductive aging: i) natural aging animals with intact ovaries (ovary-intact), ii) ovariectomized animals (OVX) and iii) a more recent model induced by the administration of 4-vinylcyclohexene diepoxide (4-VCD). Each model has its advantages and disadvantages (for a comprehensive review, read [1]).

4 -VCD is a metabolite of 4-vinylcyclohexene, a compound formed from the dimerization of 1,3-butadiene in the manufacture of synthetic rubber, insecticides, plasticizers, flame retardants, and antioxidants [5]. It is also applied against pests, e.g., for reduction of rodent fecundity and proliferation [6]. 4-VCD selectively targets the small preantral ovarian follicles (mainly primordial and primary follicles), leading to an accelerated follicular depletion and different degrees of ovarian failure, depending on the dose and period of investigation after the completion of 4-VCD administration [7-10]. For instance, the complete interruption of cyclicity and the morphologic evidence for reproductive senescence (total absence of oocytes) occurs only around 350-360 days after 4-VCD treatment in rats [8]. Thus, 4-VCD-treated rodents become an interesting preclinical model for studying the transitional estropause. 4-VCD-treated rodents have the advantage of maintaining the ovarian follicles and circulating steroid hormones more similar to those found in women under menopause transition; aspects not mimicked by the ovary-intact or OVX rodent models [1].

The vast majority of studies conducted with 4-VCD model sought to elucidate its mechanisms of action and the comprehension of the profile of ovary-derived hormones (e.g., concentrations and time-course fluctuations) [7-15]. There are few studies exposing these animals to a physiological challenge [16-18]. For instance, 4-VCD-treated mice under menopause become more responsive to the angiotensin II hypertensive effects, which do not happen during perimenopause [18]. Similarly, mice become glucose intolerant 26 weeks after 4-VCD administration [17]. In both studies, $17 \beta$-estradiol replacement normalized the impairments. $17 \beta$-estradiol has important implications on the regulation of metabolism and there is a positive relationship between perimenopause/menopause and the development of metabolicrelated derangements (for a comprehensive review, read MauvaisJarvis et al. [19]). These derangements include reduction of the energy expenditure, increased adiposity and altered adipocytokine secretory profile, $\beta$-cell dysfunction, reduced glucose disposal, which altogether may contribute to the development or exacerbation of obesity and/or type 2 diabetes mellitus [19]. Previous studies with 4-VCD-treated mice have not shown a significant alteration in the glucose metabolism (e.g., glycemia, insulinaemia and triacylglyceridemia) in normal animals [16,17]. However, the biological system may mask certain vulnerabilities while it is not submitted to certain stressing or challenging conditions, e.g., exposure to diabetogenic hormones.

Glucocorticoids (GCs) are among the most effective diabetogenic hormones and there is substantial evidence with humans and rodents treated with synthetic GC (e.g., dexamethasone) in different contexts (acutely with high doses or chronically with low doses) demonstrating its impact on glucose and lipid metabolism such glucose intolerance, reduction of insulin sensitivity, elevation in blood glucose, plasma insulin and triacylglycerol levels, etc. (reviewed in [20-22]). We have a well-established model of rats treated with dexamethasone that exhibit prediabetes like phenotype (e.g., glucose intolerance, insulin resistance, elevation in blood glucose, plasma insulin, glucagon, tryacilglycerol levels) [23-25], which serves as a good model to stress the glucose homeostasis.

Thus, based on the evidence that 4-VCD administration in immature rats leads to ovarian failure, which may turn these animals vulnerable to metabolic insults [17], we sought to explore whether 4-VCD-treated rats are more susceptible or not to the well-known adverse effects of dexamethasone on glucose homeostasis during a period considered as estropause (168-173 days after completion of 4-VCD treatment). By treating Wistar rats with 4VCD early in life and exposing them to a short-term highdexamethasone treatment as adults, we were able to show that reduced ovarian function has no major implications on the diabetogenic effects promoted by GC treatment, indicating that other factors related to aging may turn rats more vulnerable to GC side effects on glucose metabolism.

\section{Materials and methods}

\subsection{Ethical approval}

The experiments with rats were approved by the Federal University of Santa Catarina Committee for Ethics in Animal Experimentation (approval ID: PP00782 and PP00842) that is in accordance with the National Council for Animal Experimentation Control (CONCEA).

\subsection{Materials}

4-Vinylcyclohexene diepoxide was purchased from SigmaAldrich (St. Louis, MO, USA). Dexamethasone phosphate (Decadron ${ }^{\mathbb{R}}$ ) was purchased from Aché (Campinas, SP, Brazil). Regular human recombinant insulin (Humulin ${ }^{\mathbb{R}}$ ) was acquired from Lilly (Indianapolis, IN, USA). The reagents used in the glucose tolerance test, hepatic glycogen and fat content protocols, fat lipolysis protocol, and histology and immunochemistry were acquired from LabSynth (Diadema, SP, Brazil) and Sigma. Plasma insulin was quantified by AlphaLISA ${ }^{\circledR}$ technology (PerkinElmer, Waltham, MA, USA-cat. no. AL204). Plasma $17 \beta$-estradiol was determined by ELISA (DRG International, Inc., Springfield, NJ, USA-cat. no. EIA2693). Plasma progesterone was determined using specific MP kits (MP Biomedicals; Orangeburg-NY, USA, cat. no. 07DE9988) [15]. Enzymatic colorimetric assay for the quantification of triacylglycerol, total cholesterol and lactate were from Biotécnica (Varginha, MG, Brazil-cat. no. BT1001000). Primary antibodies for insulin (sc9168) and the $\mathrm{ABC}$ staining system (ImmunoCruz ${ }^{\mathrm{TM}}$ ) (sc-2018) were from Santa Cruz Biotechnology (Santa Cruz, CA, USA).

\subsection{Animals}

Experiments were performed on 3 groups of 40 female Wistar rats accounting for a total of 120 rats. The post-weaned rats were obtained from the Federal University of Santa Catarina Animal Breeding Center and were kept at $21 \pm 2{ }^{\circ} \mathrm{C}$ on a 12-h light-dark cycle (lights on at 0600 , lights off at 1800 ). Rats had access to food 


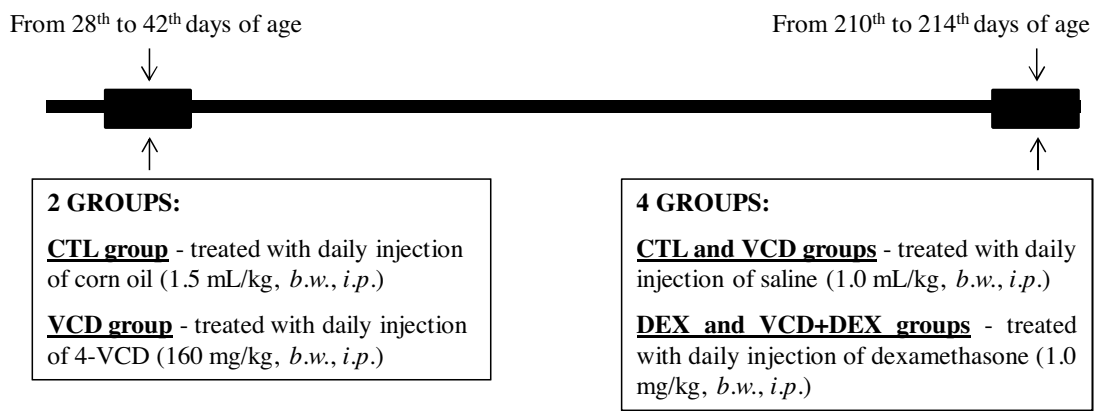

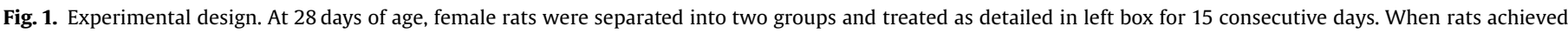

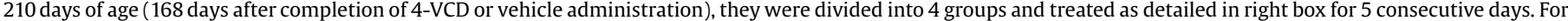
more detail, read Materials and Methods.

(commercial standard chow for rats, BIOBASE ${ }^{\circledR}$ 9301; Águas Frias, SC, Brazil) and water ad libitum.

\subsection{4-VCD and dexamethasone treatments}

According to Fig. 1, post-weaned rats (21 days of age) were housed for acclimatization for 7 consecutive days and then were separated in two groups: VCD group-received a daily intraperitoneal (i.p.) injection of 4-VCD [160 $\mathrm{mg} / \mathrm{kg}$, body weight (b.w.)], between 0700 and $0800 \mathrm{~h}$, for 15 consecutive days (from the 28th to 42nd days of age); CTL group-received a daily i.p. injection of corn oil $(1.5 \mathrm{~mL} / \mathrm{kg}$, b.w.), between 0700 and $0800 \mathrm{~h}$, for 15 consecutive days (from the 28th to 42 nd days of age). These rats were used for evaluation of some behavior parameters (e.g., ingestive responses in the open field and performance during an object recognition task) in a set of separated studies when they achieved around 90 days of life. Such behavioral experiments were not included in this study. None of the behavior parameters evaluated and animal handling is known to cause any kind of permanent stress in rats [26,27]. When rats achieved 210 days of age (168 days after completion of 4-VCD administration) they were divided into 4 groups: CTL group-received a daily i.p. injection of $\mathrm{NaCl} 0.9 \%(1 \mathrm{~mL} / \mathrm{kg}$, b.w.), between 0700 and $0800 \mathrm{~h}$, for 5 consecutive days; DEX group-received a daily i.p. injection of dexamethasone phosphate $(1 \mathrm{mg} / \mathrm{kg}, b . w$.$) , between 0700$ and $0800 \mathrm{~h}$, for 5 consecutive days; VCD group-received a daily i.p. injection of $\mathrm{NaCl} 0.9 \%$ as CTL group, and VCD-DEX group-received a daily i.p. injection of dexamethasone as DEX group. The 4-VCD and dexamethasone dosing were based on previous publications [28-31]. Administration of 4-VCD during post-weaning window is known to render a state of early perimenopause and menopause when rats exceed around 60 and 120 days $[8,15]$, which made this an useful experimental model for investigation of the effects of reduced ovarian function without aging as a confounding factor or the abrupt cessation of circulating ovarian hormones in ovariectomized rats [1]. Dexamethasone at the dose and period administered is known to produce significant glucose metabolism side effects including glucose intolerance and reduction of insulin sensitivity, which make this a valuable tool for challenging glucose metabolism experimentally [23,24,30-32].

\subsection{Metabolic measurements}

Body weight was measured weekly, from 7 weeks before the beginning of dexamethasone administration, in order to check for 4-VCD treatment effects.Then, body weight and food intake were followed daily in the last 7 days before the euthanasia, which included the 5 days of dexamethasone administration. Fasted (12-14 h) rats had blood collected from the tail to measure blood glucose levels with a glucometer (Accu-Check ${ }^{\circledR}$ Performa; Roche Diagnostics GmbH, Mannhein, Germany). Immediately after blood collection, rats were euthanized (exposure to $\mathrm{CO}_{2}$ followed by decapitation), and the trunk blood was collected in EDTA-NaFcontaining tubes (Glistab-Labtest; Lagoa Santa, MG, Brazil) to obtain the plasma. The plasma, obtained after blood centrifugation $(600 \mathrm{~g})$, was stored at $-80^{\circ} \mathrm{C}$ for posterior measure of plasma insulin, $17 \beta$-estradiol, progesterone, triacylglycerol, total cholesterol and lactate with the kits and methods described before according to the manufacturer's instructions. Organs (listed in Table 1) were gently withdrawn and weighed.

\subsection{Determination of insulin sensitivity by the homeostatic model assessment (HOMA) and triacylglycerol and glucose index (TyG)}

HOMA was calculated using the following formula: [fasting glycemia $(\mathrm{mM}) \times$ fasting insulinemia $(\mu \mathrm{U} / \mathrm{mL})] / 22.5$ and TyG index was calculated using the following formula: Ln[fasting triacylglyceridemia $(\mathrm{mg} / \mathrm{dL}) \times$ fasting glycemia $(\mathrm{mg} / \mathrm{dL}) / 2$ ] as previously published [32].

Table 1

Metabolic-associated and glucocorticoid-responsive organ mass (g/100 g b.w.) in CTL, VCD, DEX and VCD + DEX rats.

\begin{tabular}{|c|c|c|c|c|}
\hline & CTL & VCD & DEX & $\mathrm{VCD}+\mathrm{DEX}$ \\
\hline Retroperitoneal $^{\mathrm{a}}$ & $1.90 \pm 0.19$ & $2.23 \pm 0.12$ & $2.07 \pm 0.13$ & $1.79 \pm 0.15$ \\
\hline Perigonadal $^{\mathrm{a}}$ & $1.19 \pm 0.13$ & $1.37 \pm 0.09$ & $1.39 .5 \pm 0.09$ & $1.29 \pm 0.12$ \\
\hline Omental $^{\mathrm{a}}$ & $0.13 \pm 0.01$ & $0.13 \pm 0.01$ & $0.14 \pm 0.02$ & $0.13 \pm 0.01$ \\
\hline Liver & $2.59 \pm 0.05$ & $2.52 \pm 0.05$ & $4.13 \pm 0.08^{* * *}$ & $3.99 \pm 0.0 .14^{* *}$ \\
\hline Spleen & $0.23[0.201-0.25]$ & $0.20[0.19-0.22]$ & $0.14[0.16-0.16]^{* * *}$ & $0.14[0.14-0.15]^{* *}$ \\
\hline Adrenal $^{\mathrm{a}, \mathrm{b}}$ & $30[30-40]$ & $30[30-40]$ & $25[20-30]^{* *}$ & $30[27-30]$ \\
\hline
\end{tabular}

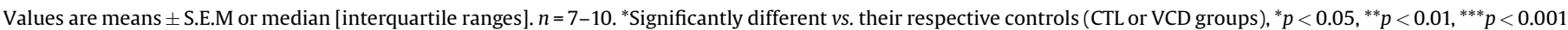

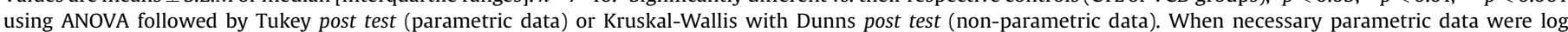
transformed to achieve homocedasticity.

a Both bilateral organs were weighed.

b $\mathrm{mg} / 100 \mathrm{~g}$ b.w. 


\subsection{Liver glycogen}

Determination of hepatic glycogen content was performed according to previous publications with a few modifications $[23,30]$. Glycogen was determined by a phenol-based assay using a spectrophotometer. Determination of hepatic triacylglycerol content was in accordance with Gonçalves-Neto and colleagues [33]. Briefly, liver samples were transferred to test tubes containing $0.7 \mathrm{~mL} 1 \mathrm{M} \mathrm{NaCl}$ and homogenized with T18 UltraTurrax ${ }^{\circledR}\left(\right.$ IKA $^{\circledR}$; Staufen, Germany). Then, methanol/chloroform solution $(1: 2 \mathrm{v} / \mathrm{v})$ was added and the tubes were subsequently centrifuged. The methanolic phase was then transferred to another test tube and after wet the solution with in $\mathrm{N}_{2}$ a solution of methanol/Triton 100 $(1: 2 \mathrm{v} / \mathrm{v})$ was added to the samples for determination of hepatic triacylglycerol content that was normalized by the tissue fragment.

\subsection{Intraperitoneal glucose tolerance test (ipGTT) and in vivo glucose- stimulated insulin secretion}

Separate groups of fasted (12-14 h) rats were used for the ipGTT experiments. Conscious rats had their tail tip cut for blood collection. The first drop was discarded, and the second drop was used for the determination of glycemia (time 0 ) using a glucometer as described before. A $50 \%$ glucose solution pre-warmed at $36^{\circ} \mathrm{C}$ $(2 \mathrm{~g} / \mathrm{kg}$, b.w., i.p.) was immediately administered, and blood samples were collected from the tail tip at 20,40, 80 and $120 \mathrm{~min}$ for blood glucose measurements [23,30,31]. At minute 20 , additional blood volume $(60 \mu \mathrm{L})$ was collected in EDTA-NaF-containing tubes for plasma separation and posterior quantification of insulin as a measure of the in vivo glucosestimulated insulin secretion $[23,24]$.

\subsection{Oral glucose challenging and in vivo glucose-stimulated insulin secretion}

To evaluate the contribution of incretin glucagon-like peptide (GLP)-1 in the insulin response to the in vivo glucose stimulation, we performed a set of experiments in a separated group of rats. Rats were fasted and had glycemia (time 0 ) quantified as described before as for ipGTT. Immediately after, rats received an oral bolus of $50 \%$ glucose solution $(2 \mathrm{~g} / \mathrm{kg}$, b.w., oralgastric gavage) and $20 \mathrm{~min}$ after had their glycemia verified. Immediately, they were euthanized as described before for collection of trunk blood and determination of plasma insulin as a measure of the in vivo glucose-stimulated insulin secretion [24].

\subsection{Adipose tissue lipolysis}

This assay was performed with the same groups of rats used in Sections 2.5-2.7. After euthanasia the ex vivo adipose tissue lipolysis was assayed by incubating tissue samples and evaluating glycerol release into the incubation medium [32,34]. Perigonadal adipose tissue fragments $(100 \mathrm{mg})$ were incubated in aerated $(5 \%$ $\mathrm{CO}_{2}: 95 \% \mathrm{O}_{2}$ ) Krebs buffer ( $\mathrm{pH} 7.4$ ) containing $1 \%$ bovine serum albumin for $60 \mathrm{~min}$ at $37^{\circ} \mathrm{C}$ in the presence or absence of $20 \mu \mathrm{mol} /$ $\mathrm{L}$ isoproterenol. At the end of the incubation, samples were collected and kept on ice. Glycerol levels were determined by an enzymatic colorimetric assay, similar to that described for plasma triacylglycerol.

\subsection{Ovarian and pancreas tissue morphology and morphometry}

To study morphological and morphometrical aspects of ovary and endocrine pancreas, 6 pars of ovaries and 6 pancreases (splenic fragment) from each group in a random selection were excised and processed according to a previous description [24,31] with the exception that the fixative solution used for ovaries' fixation was $4 \%$ paraformaldehyde and for pancreases' fixation was $10 \%$ neutral buffered formalin. The organs were withdrawn from rats subjected to the oral glucose challenging. Histology and immunostaining: Ovary morphology was observed in hematoxylin \& eosin stained sections. Pancreas sections were immunostained with insulin by the immunoperoxidase method and counterstained with hematoxylin according previous publication [24,31]. Follicular ovarian morphometry: For identification of 4-VCD effects on follicular development, three interspaced $(250 \mu \mathrm{m})$ sections per ovary were cut and had preantral follicles and Corpus luteum counted, according to the classification described by Luo and collaborators [35]. Then, their relative masses (\% of ovarian section) were multiplied by the ovarian weigh to obtain the absolute volume (in $\mathrm{mm}^{3}$ ) according to Juliani et al. [36]. Beta-cell mass: Beta-cell mass was determined by point counting morphometry on each pancreas section immunostained for insulin, according previous descriptions $[24,31]$. Each section was systematically scored with a grid of 120 points (final magnification $\times 200$ ). An average of 250 fields per pancreas was counted. All the images for documentation were registered by a CCD camera coupled to a BX-60 Olympus photomicroscope.

\subsection{Statistical analysis}

The results are expressed as the mean \pm SEM of the indicated number $(n)$ of experiments. The symmetry of the data was tested by Kolmogorov-Smirnov and Shapiro-Wilk normality tests. Analysis of variance (ANOVA) (one-way ANOVA) for unpaired groups followed by Tukey's post hoc test were utilized for multiple comparisons of parametric data or Kruskal-Wallis followed by Dunn's post hoc when variables achieved asymmetric distribution. When indicated, data were log transformed for parametric analysis. ANOVA for repeated measures was applied when it was the case. Unpaired or paired Student's t-test or unpaired Mann-Whitney tests were applied when necessary. Extreme studentized deviate method was applied to determinate whether one of the values reached significant outlier (Grubb's test from online available GraphPad QuickCalcs). Reference in the text to "their respective control groups" means differences among DEX and VCD-DEX groups vs. CTL and VCD groups, respectively (effect of dexamethasone), or VCD and VCD-DEX groups vs. CTL and DEX groups, respectively (effect of $4-\mathrm{VCD}$ ). Significance was set at $p<0.05$.

\section{Results}

\subsection{Effects of 4-VCD treatment on ovaries}

To confirm the biological effects of 4-VCD treatment early in life on the adult reproductive function we determined several reproductive-related parameters. The relative ovary weight (the sum of both glands), at the euthanasia, was significantly reduced in the 4-VCD-treated rats compared with their respective control groups (CTL and DEX) $(p<0.01$; Fig. $2 \mathrm{~A})$. The values were $33.2 \pm 1.7$, $24.0 \pm 1.0,31.8 \pm 1.0$ and $24.6 \pm 1.0 \mathrm{mg} / 100 \mathrm{~g}$ b.w. for the CTL, VCD, DEX and VCD + DEX groups, respectively. Plasma $17 \beta$-estradiol levels were ELISA-positive (nearing the lowest standard curve point of $25 \mathrm{pg} / \mathrm{mL}$ ) in 4 from 10 samples (CTL group), none of 10 samples (VCD group), 1 from 10 samples (DEX group) and 1 from 10 samples (VCD + DEX groups). Plasma progesterone levels were not altered by 4 -VCD treatment, but increased 18 -fold in DEX vs. CTL groups $(p<0.001)$, an effect not observed in rats previously treated with 4-VCD (Fig. 2B). A panel of ovary tissue morphology emphasizing the reduction of preantral follicles and Corpus luteum 
A
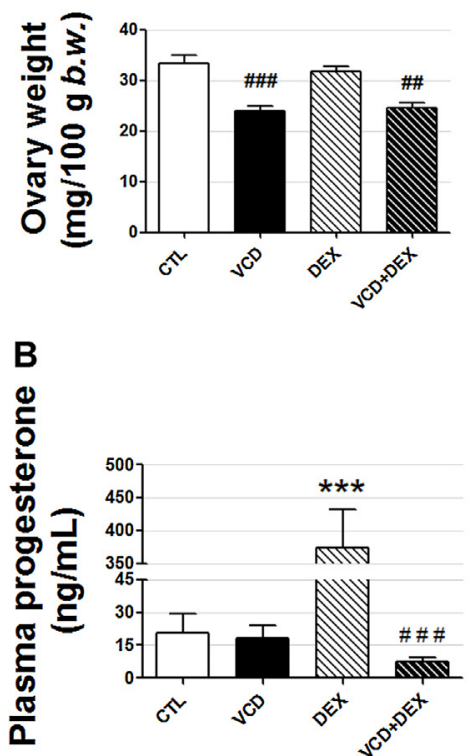

C
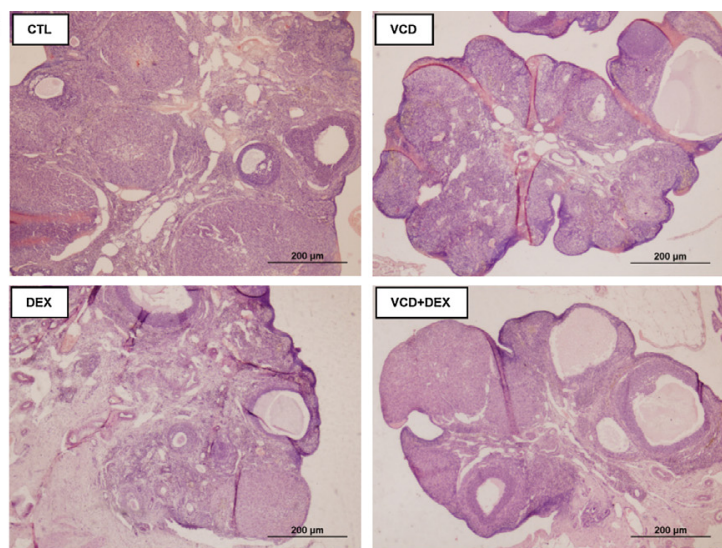

D

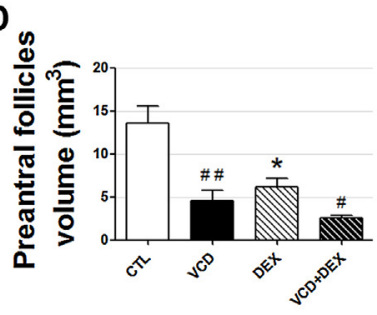

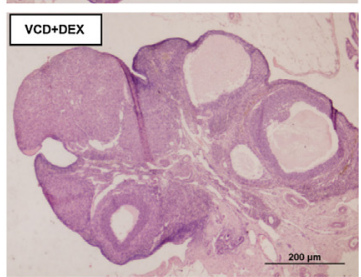

E

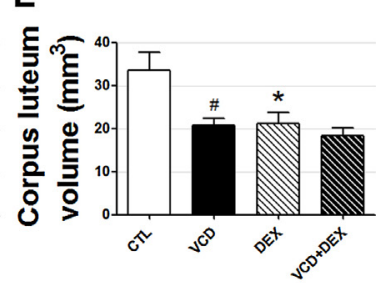

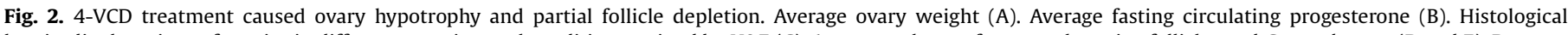

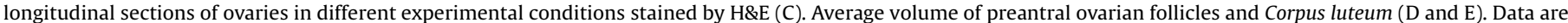

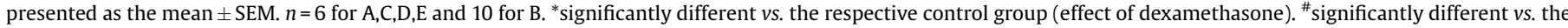

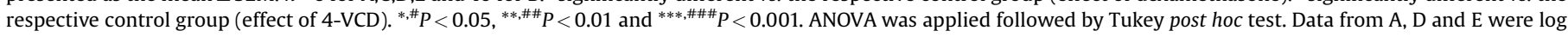
transformed before statistical analysis. Scale bar in $C$ means $200 \mu \mathrm{m}$ and was acquired through $4 \times$ objective.

distribution both in the 4-VCD-treated and dexamethasonetreated rats is observed in Fig. $2 \mathrm{C}(p<0.05)$. The preantral and Corpus luteum volumes were quantified and the values can be observed in Figs. 2D and E. Based on that, we assume that 4-VCD treatment promoted ovary hypotrophy and reduced ovarian function in adulthood (173 days of age), which is compatible with the characteristics of estropause [8].

\subsection{Murinometric and metabolic characteristics in the 4-VCD-treated rats}

To verify whether 4-VCD treatment has any impact on murinometric and metabolic adverse effects caused by dexamethasone treatment, we evaluated several parameters. There were no differences in body weight between the CTL and VCD groups during the last 7 weeks before the beginning of dexamethasone treatment (Fig. 3A). During dexamethasone treatment, body weights were significantly reduced after $24 \mathrm{~h}$ and remained with a sustained reduction until euthanasia in DEX and VCD + DEX $v s$. CTL and VCD groups, respectively $(p<0.01)$. No differences in the final body weight were observed between the 4-VCD-treated rats and their respective controls (Fig. $3 \mathrm{~B}$ and $\mathrm{C}$ ). On the day before euthanasia, the body weight in the dexamethasone-treated rats was about $10 \%$ lower than in the control groups. Food intake was similar among the four groups before the initiation of dexamethasone treatment. Food intake was significantly lower in the dexamethasone-treated rats after $48 \mathrm{~h}$ of dexamethasone administration and remained lower until the day before euthanasia $(p<0.01$; Fig. 3D and E). No alterations related to food intake were observed that could be attributed to the 4-VCD treatment. No modifications in blood glucose, plasma insulin, triacylglycerol, total cholesterol or lactate could be attributed to 4-VCD per se nor did the 4-VCD-treated rats become more vulnerable to the adverse effects caused by dexamethasone treatment on such parameters (e.g., elevation in glycemia, insulinaemia, triacylglyceridemia, lactatemia) (Fig. 4A-E). As judged by HOMA-IR and TyG indexes values, rats treated with 4 -VCD did not show alteration in the insulin sensitivity (VCD group) neither did they show exacerbated insulin insensitivity caused by GC treatment (VCD + DEX group) (Fig. 4F and G). Neither 4-VCD nor dexamethasone treatment led to changes in rat adiposity (retroperitoneal, perigonadal and omental fat), but dexamethasone, as expected, caused adrenal and spleen hypotrophy as well as enhanced liver mass $(p<0.01)$ (Table 1$)$. Altogether, reduced ovarian function caused by 4-VCD treatment had no impact on murinometric and metabolic profile per se nor worsened the adverse effects caused by GC treatment on murinometric and metabolic parameters.

\subsection{Hepatic and adipose tissue function in the 4-VCD-treated rats}

To verify whether 4-VCD treatment impact in the liver and fat function we measured the hepatic glycogen and triacylglycerol content and the glycerol released in the adipose tissue fragments. Exposure to 4-VCD early in life did not result in hepatic alterations (glycogen and triacylglycerol content) in adulthood neither did it caused additional impact when rats were treated with dexamethasone, a condition known to elevate both substrate contents (Fig. 5A and B). Ex vivo basal and isoproterenol-stimulated glycerol release was similar between CTL and VCD groups (Fig. 5C). The differences between stimulated $v s$. basal glycerol release were not observed in rats treated with dexamethasone (DEX and VCD + DEX groups) indicating a more lipolytic fat tissue at basal conditions. No differences between DEX and VCD + DEX were observed for this parameter. Thus, reduced ovarian function did not exacerbate the altered hepatic and fat functions caused by GC treatment. 

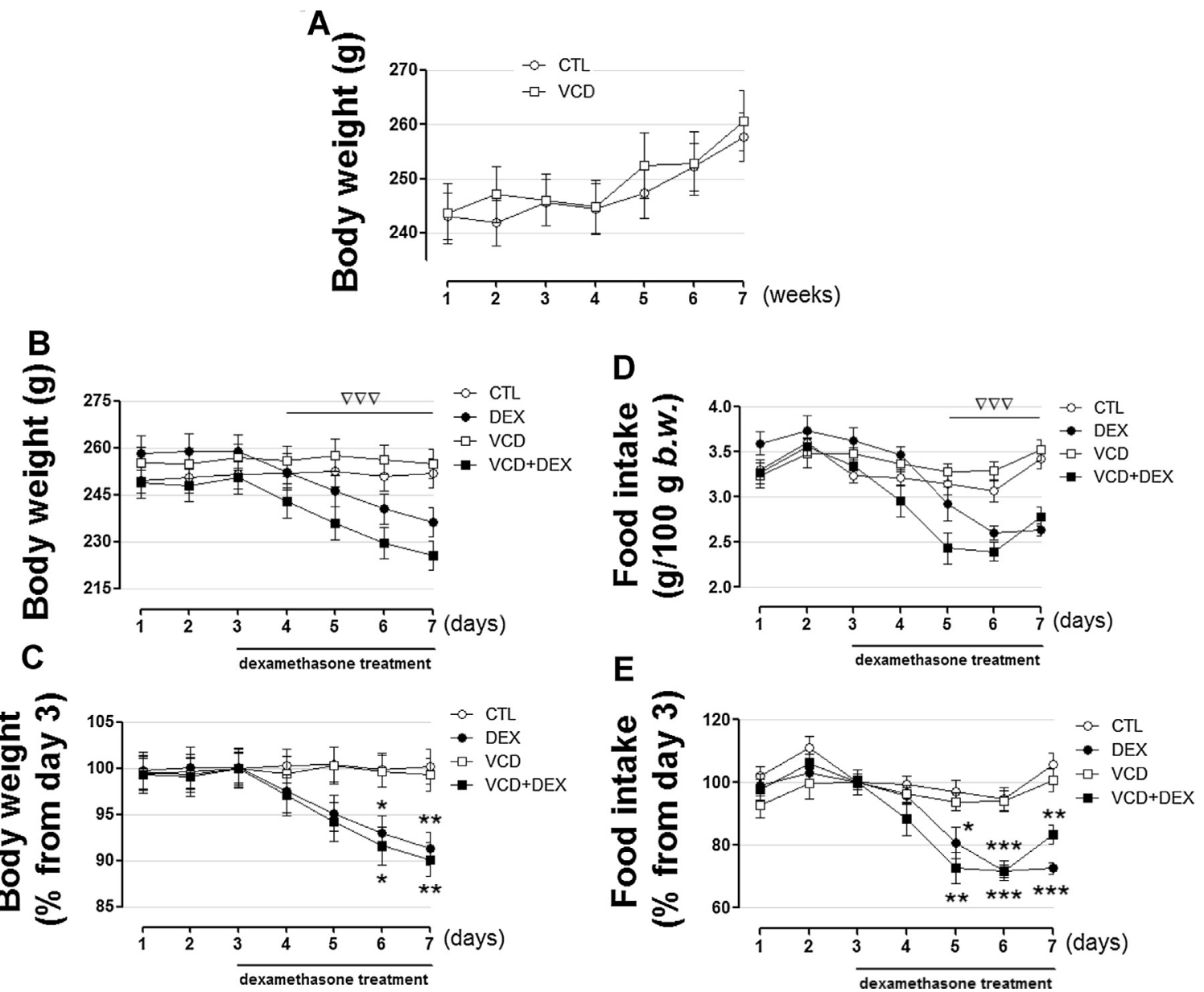

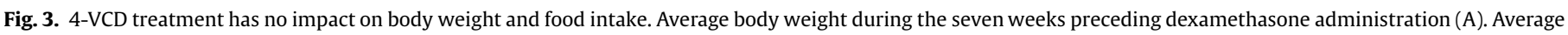

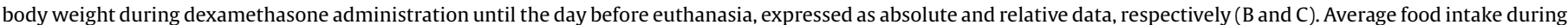

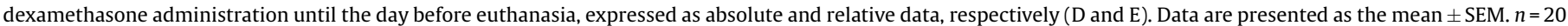

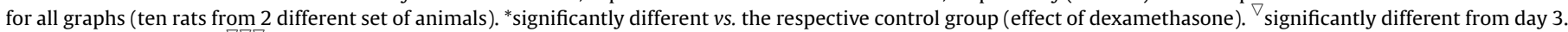

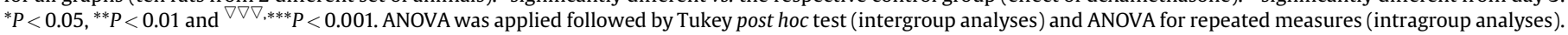

\subsection{Glucose tolerance and in vivo glucose-stimulated insulin secretion in the 4-VCD-treated rats}

Considering glucose intolerance may anticipate the elevation in blood glucose, we assessed the glucose tolerance and the insulin response to glucose in vivo. Rats treated with 4-VCD alone exhibited higher blood glucose levels $20 \mathrm{~min}$ and $40 \mathrm{~min}$ after an intraperitoneal glucose bolus than the CTL group $(p<0.05)$, indicating a negative impact of reduced ovarian function on glucose homeostasis. The blood glucose values were $372 \pm 33 \mathrm{mg} /$ $\mathrm{dL}$ for CTL group and $474 \pm 19 \mathrm{mg} / \mathrm{dL}$ for VCD group at min 20, and $328 \pm 23 \mathrm{mg} / \mathrm{dL}$ for CTL group and $435 \pm 22 \mathrm{mg} / \mathrm{dL}$ for VCD group at min 40 (Fig. 6A). 4-VCD-treated rats that received GC treatment exhibited the same glycemic profile during the ipGTT test, which indicates no incremental impact of reduced ovarian function on glucose tolerance when rats receive GC. The area-under-curve of blood glucose values (A.U.C) revealed glucose intolerance in the VCD, DEX and VCD + DEX groups $(p<0.05$; Fig. $6 \mathrm{~B})$. This glucose intolerance was associated to the reduced insulin response to glucose (at min 20 of ipGTT) in the VCD group ( $p=0.058)$ and a relative deficiency (insufficient) of insulin secretion in those rats made insulin-insensitive due to the GC treatment (DEX and VCD + DEX groups) (Fig. 6C). The glucose intolerance was not reproducible in VCD rats when challenged with glucose bolus by the oral vial, since they exhibited similar circulating insulin levels 20 min after glucose load (Fig. 6D and E). The VCD + DEX group did not exhibit additional alteration in the glucose profile or insulin secretion during the oral glucose challenge compared to the DEX group (Fig. 6D and E). Although no major impact on glucose tolerance by oral challenge was observed in VCD-treated rats, caution is required when combining the GC therapy with a reduced ovarian function.

\section{5. $\beta$-cell mass in the 4 -VCD-treated rats}

To verify if a reduction in the ovarian function affects the compensatory increase in the $\beta$-cell mass in response to the diabetogenic actions of GCs, we evaluated this pancreas parameter. Treatment with 4-VCD early in life did not result in distinguished alteration of the $\beta$-cell mass in adulthood (Fig. 7A-C). When these 4 -VCD-treated rats received dexamethasone during adulthood there was no equivalent increase in the $\beta$-cell mass as observed in the DEX group. The VCD-DEX group had reduced $\beta$-cell mass compared to the DEX group ( $p<0.05$; Fig. $7 \mathrm{~A}$ and $\mathrm{B}$ ), but after normalization by the body weight, the relative $\beta$-cell mass was higher in VCD + DEX group vs. VCD group $(p<0.05$; Fig. 7C). Thus, 
A

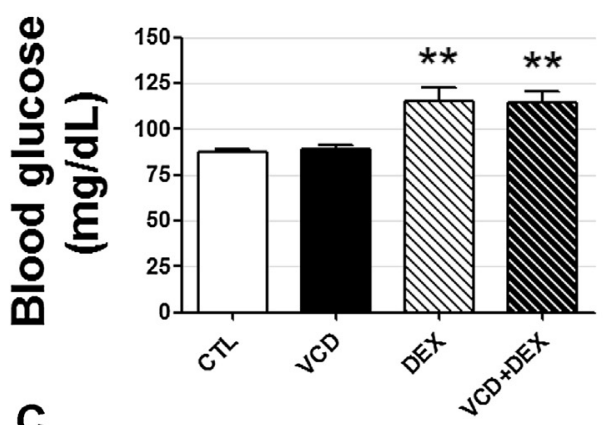

C
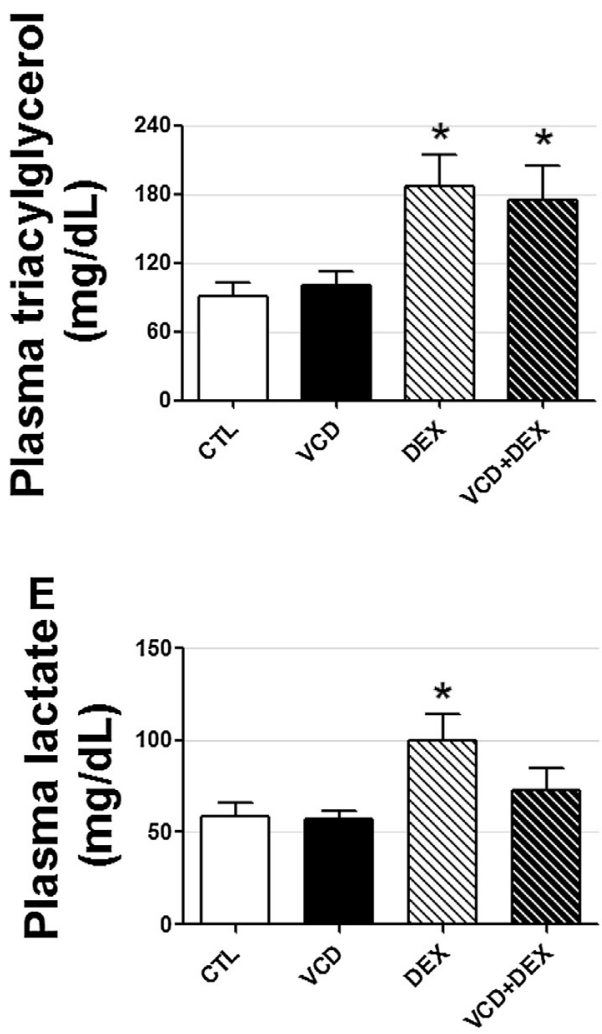

B

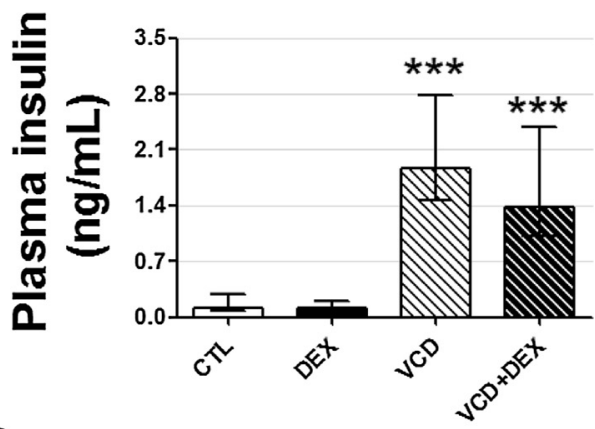

D

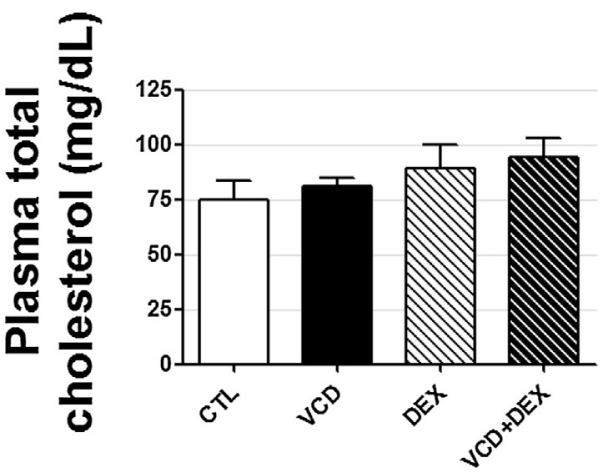

$\mathbf{F}$

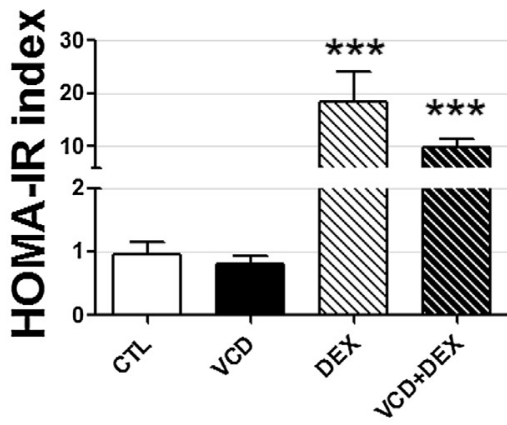

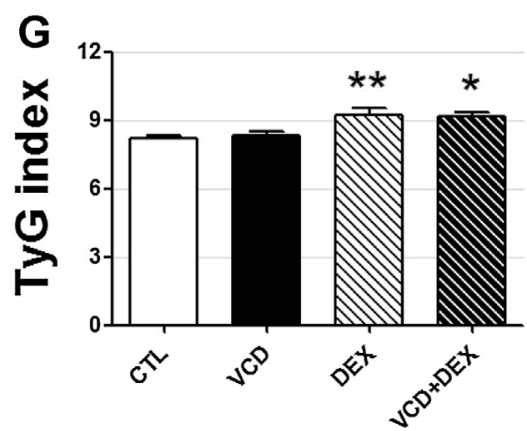

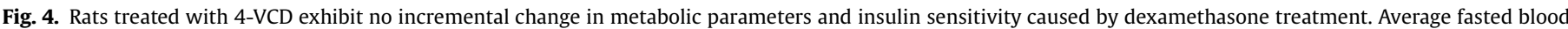

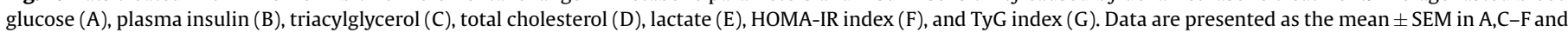

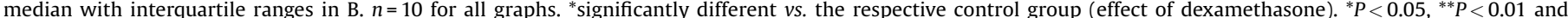

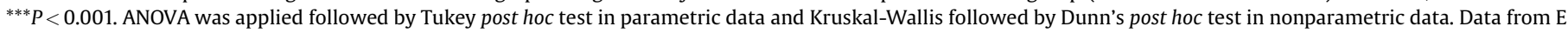
were $\log$ transformed before statistical analysis. 

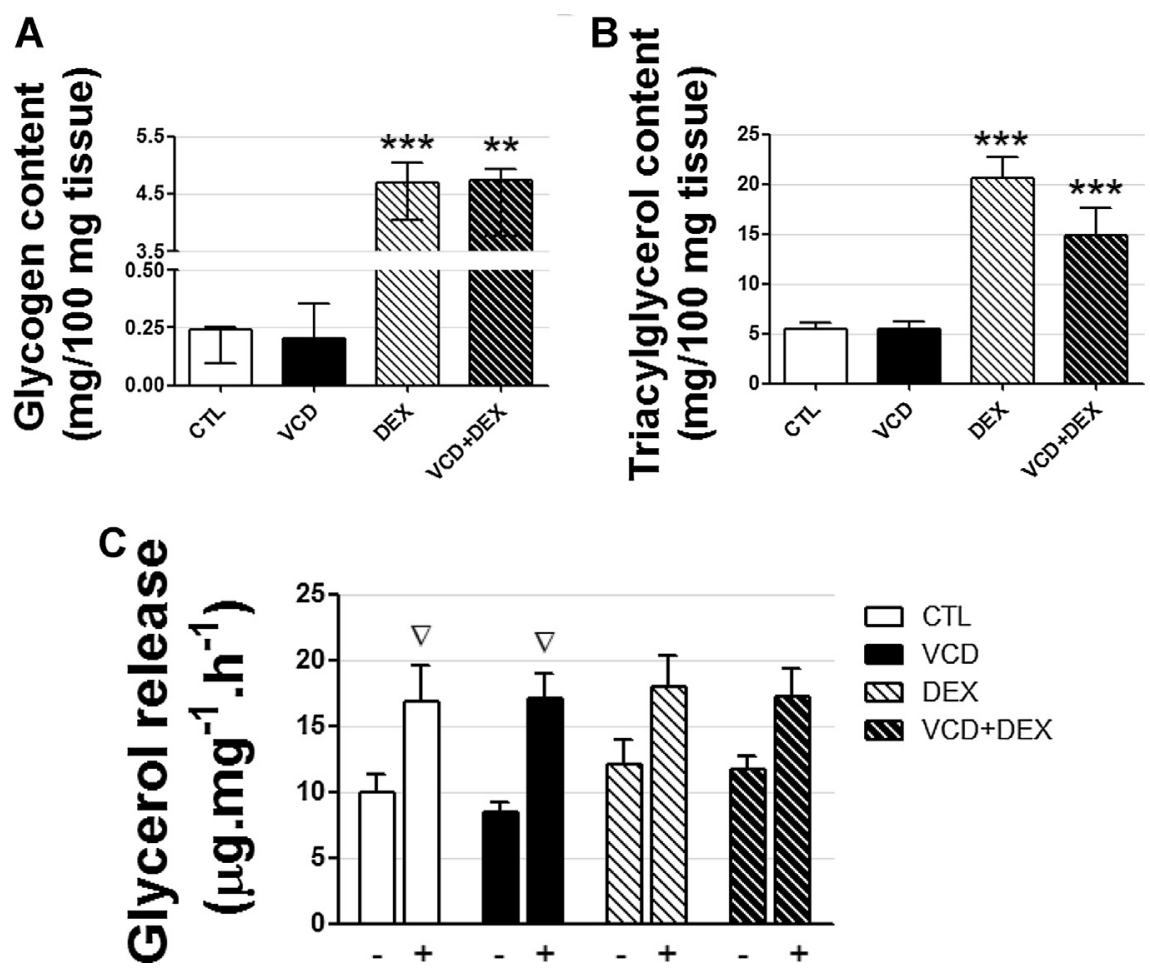

Fig. 5. Accumulation of hepatic glycogen and triacylglycerol caused by dexamethasone treatment is not worsened in rats with ovarian failure. Average hepatic glycogen (A) and triacylglycerol (B) content. In (C) average perigonadal glycerol release under basal and isoproterenol-stimulated conditions. Data are presented as the median with interquartile ranges in A and mean \pm SEM in B and C. $n=10$ for all graphs. *significantly different $v$ s. the respective control group (effect of dexamethasone). $\nabla$ significantly different from basal condition. ${ }^{\nabla} P<0.05,{ }^{* *} P<0.01$ and ${ }^{* * *} P<0.001$. ANOVA was applied followed by Tukey post hoc test in parametric data and Kruskal-Wallis followed by Dunn's post hoc test. Unpaired Student's $t$-test was also applied in C for comparison between stimulated and nonstimulated glycerol release. Data from B were log transformed before statistical analysis.
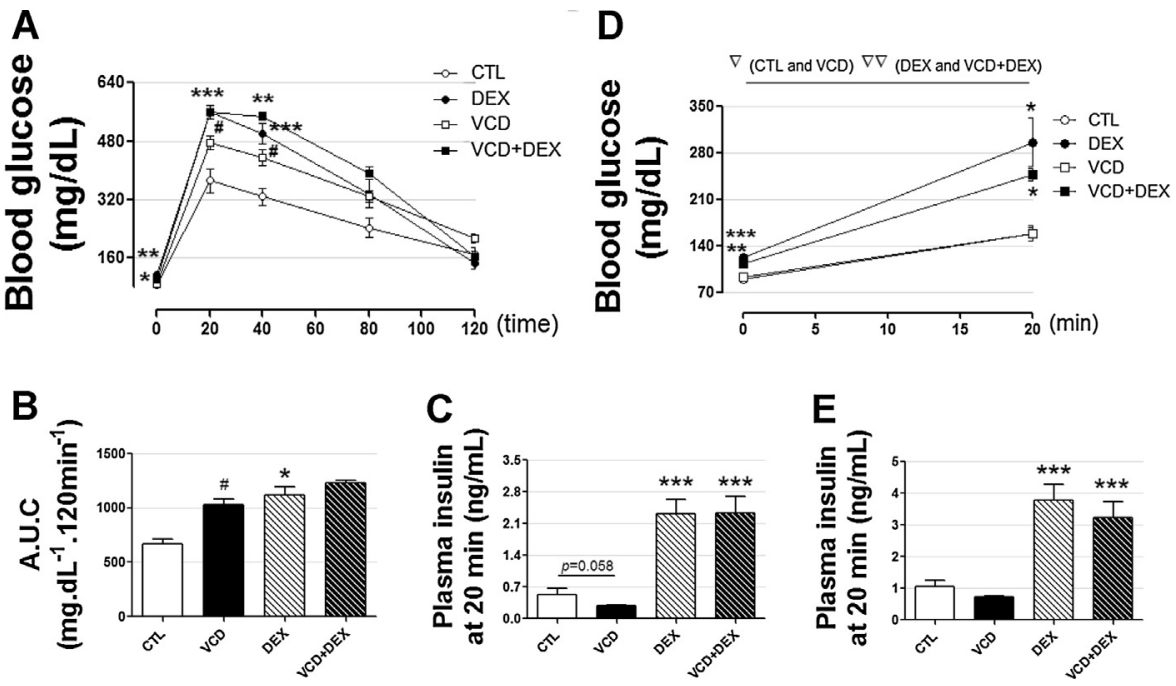

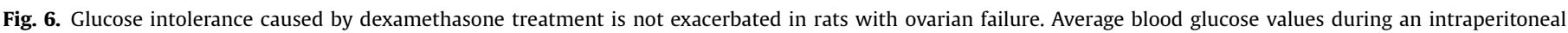

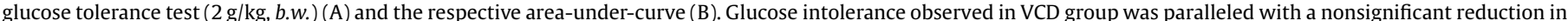

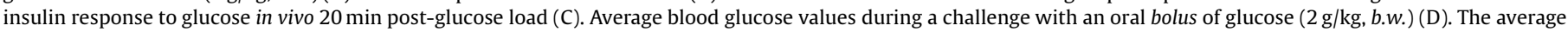

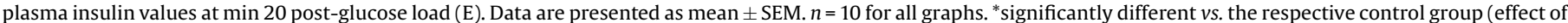

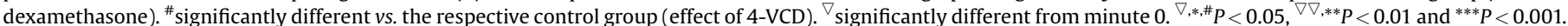

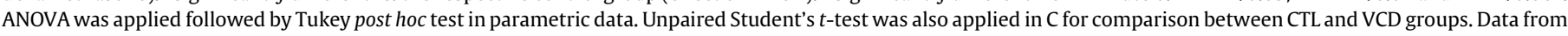
$\mathrm{C}$ and $\mathrm{E}$ were $\log$ transformed before statistical analysis. 

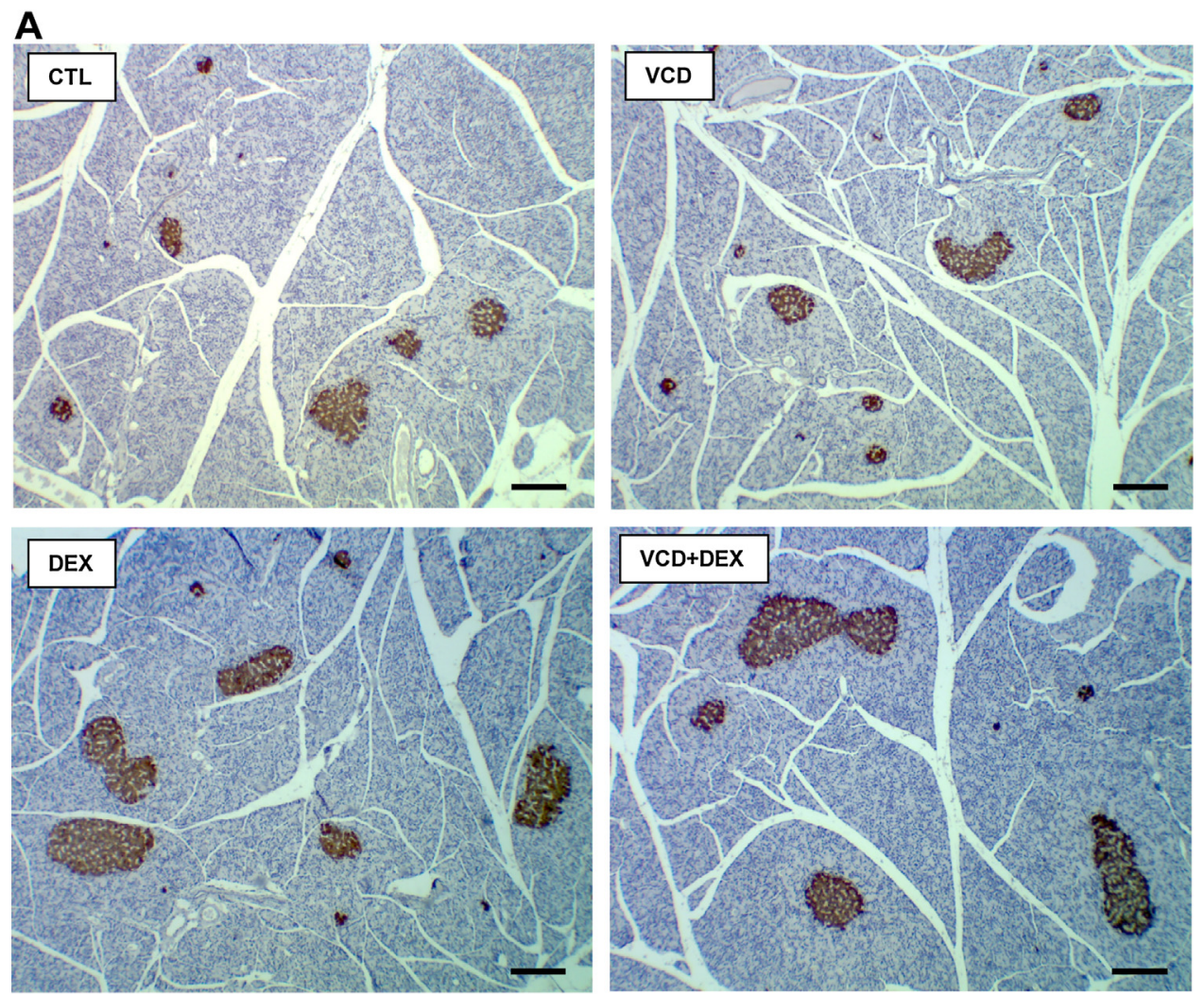

B

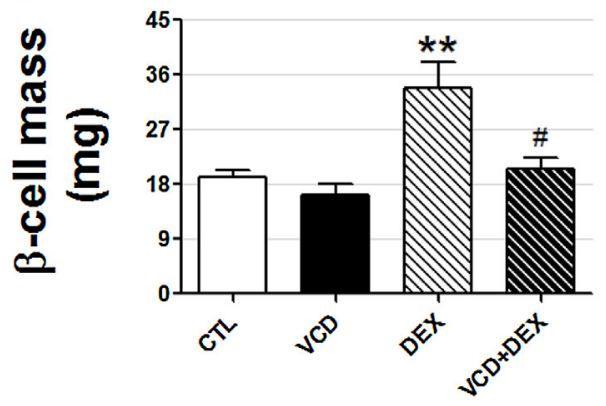

C

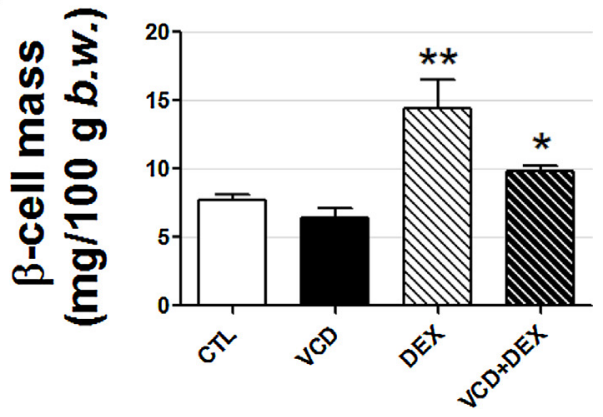

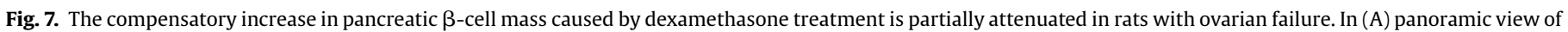

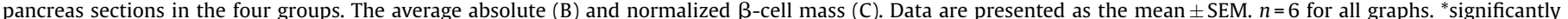

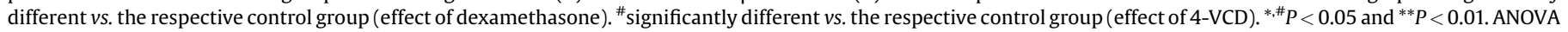

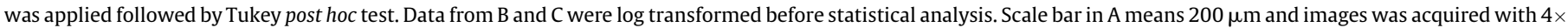
objective.

failure of ovarian function per se had no implication in the $\beta$-cell mass, but impacted on the proper endocrine pancreas ability to increase $\beta$-cell mass in a diabetogenic context.

\section{Discussion}

Estrogens play an important role in the control of energy balance and glucose homeostasis [19]. Women and laboratory rodents experience a progressive transition toward a reduction in the ovary function during the post-reproductive period of life, which culminates in an altered steroid hormone profile (e.g., decrease in $17 \beta$-estradiol levels in women and variable circulating $17 \beta$-estradiol oscillations in rodents) [1]. Reduced estrogen plasma levels and/or actions may predispose the organism to many metabolic derangements (e.g., increase in visceral adiposity, glucose intolerance and peripheral insulin resistance) [19]. Here, we have demonstrated for the first time that adult rats with premature ovarian failure (e.g., ovary hypotrophy and reduced preantral follicles volume), caused by $4-\mathrm{VCD}$ administration early in life, exhibit the same degree of GC side effects on murinometric and glucose metabolism parameters: i) loss of body weight in parallel with hypophagia, ii) augmentation in blood glucose, plasma insulin and triacylglycerol levels, iii) insulin resistance, iv) increase in hepatic triacylglycerol content, v) glucose intolerance accompanied by relative poor insulin secretory response to glucose and vi) compensatory increase in pancreatic $\beta$-cell mass (to a lesser extend in VCD + DEX group).

The effectiveness of 4-VCD administration in the VCD and $V C D+D E X$ groups was consistent with previous studies demonstrating a reduction in the ovary weight 30 days after the completion of $4-\mathrm{VCD}$ administration in adult rats $(80 \mathrm{mg} / \mathrm{kg}, b$. w., i.p.) $[37,38]$. Both studies have demonstrated a decrease in circulating $17 \beta$-estradiol and an increase in follicle-stimulating hormone (FSH) 30 days after 4-VCD treatment. The dose of 4-VCD 
administration and the time post-treatment evaluated in these studies were quite different from ours [37,38], which could explain the different results. The study conducted by Reis et al. [15] considered the periestropause period (analogous to perimenopause in women) around to 80 days after the beginning of 4-VCD treatment. Although we did not evaluate circulating FSH levels in our study (rats with 173 days of life after the beginning of 4-VCD treatment), other studies have demonstrated an increase in plasma FSH levels in rats $(80 \mathrm{mg} / \mathrm{kg}$, b.w., i.p. $)$ and in mice $(160 \mathrm{mg} / \mathrm{kg}$, b.w., i.p.) 120 days after the onset of 4-VCD administration [8,28], which is consistent with estropause (analogous to menopause in women). Only in the CTL group, 4 out of 10 plasma samples were positive for $17 \beta$-estradiol in the ELISA experiments; a frequency three to four times higher compared to the other three groups. This result are in accordance with a previous study showing that mice treated with 4-VCD ( $160 \mathrm{mg} / \mathrm{kg} \mathrm{b.w.)} \mathrm{early} \mathrm{in} \mathrm{life} \mathrm{also} \mathrm{showed} \mathrm{nondetectable}$ levels of $17 \beta$-estradiol on day 127 following the onset of 4-VCD treatment [28]. This indicates that both 4-VCD and dexamethasone treatments had a negative impact on $17 \beta$-estradiol bioavailability. The lack of estrous cycle information in our rats is a drawback of our study, but we believe the CTL group was regularly cycling, which might explain why this group presented a higher frequency of $17 \beta$-estradiol positive tests. These is corroborated by the knowledge that estrous cycle duration becomes longer in 4-VCDtreated rodents, including in mice treated with similar conditions to our model (known as more sensitive to 4-VCD) [29]. The effectiveness of ovarian failure in the 4-VCD-treated rats was also in accordance with previous studies revealing a reduction in the ovarian number of preantral follicles and Corpus luteum after 4VCD treatment [8-10,13,39]. It is important to highlight that 4-VCD treatment does not eliminate all follicles. In fact, 4-VCD-treated rats, submitted to the same protocol used in our study, present the same amount of healthy follicles, but an increased number of atresic follicles [15]. Data with circulating progesterone in the present study also indicate an ovarian failure in the 4-VCD-treated rats as the GC-induced elevation in plasma progesterone levels was abolished in the VCD+DEX group. This elevation in plasma progesterone levels in the DEX group may be a result of direct effects of GCs on progesterone biosynthesis and release from the ovaries [40,41].

Considering estrogens are involved with modulation of energy balance [19] we accompanied the body weight gain along animal's development. Ovarian failure had no significant impact on body weight gain before and during dexamethasone treatment. The significant reduction in body weight was associated to dexamethasone treatment and could be explained, at least in part, by the parallel reduction of food intake along with the GC treatment. Rats treated with dexamethasone have exhibited hyperinsulinemia $[24,25,32,34,42,43]$ and hyperleptinemia [42]. Both of which are signals to activate satiety in the hypothalamic nuclei involved in the control of appetite. There is also evidence for a negative water balance in rats treated with dexamethasone. This might contribute to body weight reduction [44]. Whether $17 \beta$-estradiol hormone had a major implication on body weight in the 4-VCD-treated rats, then an opposite scenario of augmented food intake would be expected in the VCD and VCD + DEX groups. Although there is evidence for an anorexic role of $17 \beta$-estradiol $[19,45]$, that was not the case in the present study.

Short-term treatment with dexamethasone is a valuable tool to stress and challenge the glucose homeostasis once GCs exert diabetogenic effects (e.g., hyperglycemia, hyperinsulinemia, hyperglucagonemia, hypertriacylglyceridemia, insulin resistance) in both human and rodents [20-22]. All of these metabolic alterations, except for hyperglucagonemia (not quantified in the current study), were confirmed in the dexamethasone-treated rats (DEX) while rats with reduced ovary function $(\mathrm{VCD}+\mathrm{DEX})$ did not exhibit exacerbation of such parameters. Rats treated with 4-VCD alone did not reveal any alteration on these parameters. This absence of 4-VCD impact on metabolic parameters was in accordance with previous publications showing that mice treated with 4-VCD had no alteration in blood glucose values when evaluated both during periestropause and estropause [16,17]; neither of these two studies measured circulating $17 \beta$-estradiol. An association of a high-fat diet with ovarian failure likewise did not result in a worsening of blood glucose and plasma triacylglycerol values in mice during estropause [17]. Dexamethasonemediated actions in such metabolic alterations include increase in hepatic gluconeogenesis [21,25,34], reduced adipose tissue and skeletal muscle glucose uptake [21,46], hyperglucagonemia $[21,25]$, reduced insulin signaling in peripheral tissues [34,46], increased adipose tissue glycerol release $[32,34,46]$ and reduced insulin-degrading enzyme activity in liver [47]. Although the downregulation of circulating estrogen levels or its peripheral actions impact negatively in the glucose and lipid homeostasis $[19,45]$, it seems not to be the case in the current 4-VCD rat model. It indicates that residual circulating $17 \beta$-estradiol still exerts effects and/or other components related to the aging process might implicate the estrogen downregulation on metabolic-related derangements occurring in the reproductive senescence. The mechanism by which estrogens act in this context remains unclear, but it has been proposed that the age-related shift in estrogens efficacy could be related to an alternative splicing of estrogen receptors in rats [48].

Evaluation of glycogen and triacylglycerol hepatic contents revealed no negative implication of 4-VCD administration per se or when associated with the dexamethasone challenge. Both groups receiving 4-VCD early in life presented the same hepatic content values compared to their control groups. The enhanced hepatic glycogen and triacylglycerol content in the dexamethasonetreated groups are partially explained by an alleviation of glycogen consumption due to an increased hepatic gluconeogenic action of GC $[21,25,34]$ and increased hepatic lipid biosynthesis (e.g., by stimulating the activity of acetyl-coenzyme A carboxylase and free fatty acid synthase, increasing the synthesis of VLDL, downregulating LDL receptor activity and increasing the activity of 3hydroxy-3-methylglutaryl-coenzyme A reductase) [49]. 4-VCD treatment exerted no major effects on the glycerol release from the perigonadal adipose tissue which was in accordance to their absent effect on the circulating triacylglycerol levels. The absence of significant differences between basal and isoproterenol-stimulated glycerol release in rats treated with dexamethasone is in agreement with previous studies showing similar results [34,50] and may be associated to reduced lipoprotein lipase activity [51] and augmented hormone-sensitive lipase activity [52].

Considering 4-VCD treatment promoted no major impact on basal glucose and lipid homeostasis, we challenged the rats' glucose homeostasis with an intraperitoneal glucose tolerance test (ipGTT), a method for evaluation of insulin secretory capacity (without contribution of incretin hormones), peripheral insulin sensitivity and glucose effectiveness [53]. The VCD group became glucose intolerant as observed by AUC values, obtained during ipGTT, and it was associated with a reduced insulin secretory response to in vivo glucose stimulation. However, no alteration in blood glucose levels was observed after a 20 min challenge with an oral bolus of glucose, which was paralleled with a normal insulin secretory response in vivo. Treatment with 4-VCD did not worsen the glucose intolerance induced by dexamethasone administration. Thus, excluding the incretin contribution to the potentiation of glucose-stimulated insulin secretion, the VCD group seemed to have an impairment of the secretory process. This is in accordance to the evidence that $17 \beta$-estradiol, through estrogen receptor $\beta$, augment glucose-stimulated insulin secretion [54]. In agreement 
with that, estropaused mice exhibit glucose intolerance 24 weeks after 4-VCD treatment when submitted to an ipGTT. However, this is normalized after $17 \beta$-estradiol replacement [17], showing the consequence of estrogens deficiency on glucose homeostasis. Santos et al. [31] have demonstrated that 12-month old female rats become insulin resistant and show reduced islet insulin secretory response to glucose. Although these authors did not measure circulating estrogens, they suggested that steroid hormones may be involved with the reduced islet response to glucose.

The VCD + DEX group responded to the ipGTT and oral challenge with a bolus of glucose in a similar way to the DEX group. This resembling response may be explained by their capacity to increase the pancreatic $\beta$-cell mass (when normalized by their body weight) in response to the reduced peripheral insulin sensitivity. Although the magnitude of this adaptive islet compensation in VCD + DEX group was different from the DEX group, it was enough to avoid the exacerbation of glucose intolerance caused by GC administration. Estrogens are implicated in the maintenance of pancreatic $\beta$-cell formation and replication during metabolic injury [55]. Thus, we cannot discard that $\mathrm{VCD}+\mathrm{DEX}$ group retained residual levels of estrogen, enough to play a role on the relative compensatory increase in the $\beta$-cell mass. Moreover, they could have exhibited an upregulation of estrogen receptors or signaling in the pancreatic $\beta$ cells. Indeed, estrogens are important to the physiological maintenance of $\beta$-cell mass. Ovariectomized rats exhibit reduction in the $\beta$-cell mass and this impairment is recovered by $17 \beta$-estradiol replacement [45].

Altogether, these results demonstrated a reduction in the ovarian function based on ovary hypotrophy, reduced number of preantral follicle and Corpus luteum, and abolishment of progesterone elevation induced by GC. The adverse effects of dexamethasone on glucose metabolism (e.g., glucose intolerance, insulin resistance, dyslipidemia) were not worsened by the treatment with 4-VCD early in life. Therefore, we conclude that premature ovarian failure in adult rats does not exacerbate the negative impact of GC on glucose and lipid metabolism. These data suggest that there is a residual action of estrogens in the 4-VCD model for rats and other components present during aging might act conjunctly with estrogen deficiency to cause the metabolic derangements associated with estropause in rats.

\section{Conflict of interest}

The authors declare no conflict of interest.

\section{Authorship contributions}

Participated in research design: A.R. and F.B.L. Conducted experiments: A.M.B., A.R., C.S, E.C.R.L., F.G.B, S.R.T. and S.S. Contributed with analytic tools and data analysis: A.R., F.B.L. and F.G.B. Performed data collection and interpretation: A.R., F.B.L. and F.G.B. Provided reagents/materials: A.R., F.B.G. and J.A.A-F. Wrote the paper: A.R. Contributed to discussion: A.R. and F.B.L. All authors read and approved manuscript final format.

\section{Funding}

A.R. was provided with laboratory rats from the Federal University of Santa Catarina-UFSC. Almost all reagents and materials were provided by personal A.R. earnings. F.B.G. provided the estradiol ELISA kit by her own earnings. Part of glucometer strips was provided by the Multicenter Graduate Program in Physiological Sciences.

\section{Acknowledgments}

The authors appreciate the technical assistance during experimental procedures of Laboratory of Investigation in Chronic Diseases-LIDoC's staff. We also thank Ruither de Oliveira Gomes Carolino for technical support with the progesterone assay and Jeffrey M. Christian, who reviewed the English in the manuscript. A.M.B, C.S. and S.S. received fellowships from National Council for Scientific and Technological Development-CNPq and from Coordination for the Improvement of Higher Education PersonnelCAPES during the period of study conduction. A.R. is sponsored by CNPq (302261/2014-1).

\section{References}

[1] S.V. Koebele, H.A. Bimonte-Nelson, Modeling menopause: the utility of rodents in translational behavioral endocrinology research, Maturitas 87 (2016) 5-17.

[2] L. Butler, N. Santoro, The reproductive endocrinology of the menopausal transition, Steroids 76 (2011) 627-635.

[3] Global Health Observatory (GHO) (Internet), World health Organization. http://www.who.int/gho/mortality_burden_disease/life_tables/ situation_trends/en/ (accessed 29.03.16).

[4] J.M. Goldman, A.S. Murr, R.L. Cooper, The rodent estrous cycle: characterization of vaginal cytology and its utility in toxicological studies, Birth Defects Res. B Dev. Reprod. Toxicol. 80 (2007) 84-97.

[5] International Agency for Research on Cancer, 4-Vinylcyclohexene, IARC Monogr. Eval. Carcinog. Risks Hum. 60 (1994) 347-359.

[6] C. Dyer, R. Raymond-Whish, S. Schmuki, T. Fisher, B. Pyzyna, A. Bennett, L.P. Mayer, Accelerated follicle depletion in vitro and in vivo in Sprague-Dawley rats using the combination of 4-vinylcyclohexene diepoxide and triptolide, J. Zoo Wildl. Med. 44 (2013) S9-S17.

[7] J.A. Flaws, J.K. Doerr, I.G. Sipes, P.B. Hoyer, Destruction of preantral follicles in adult rats by 4-vinyl-1-cyclohexene diepoxide, Reprod. Toxicol. 8 (1994) 509514.

[8] L.P. Mayer, N.A. Pearsall, P.J. Christian, P.J. Devine, C.M. Payne, M.K. McCuskey, S. L. Marion, I.G. Sipes, P.B. Hoyer, Long-term effects of ovarian follicular depletion in rats by 4-vinylcyclohexene diepoxide, Reprod. Toxicol. 16 (2002) 775-781.

[9] K.E. Thompson, I.G. Sipes, B.D. Greenstein, P.B. Hoyer, 17 beta-estradiol affords protection against 4-vinylcyclohexene diepoxide-induced ovarian follicle loss in Fischer-344 rats, Endocrinology 143 (2002) 1058-1065.

[10] Z. Chen, X. Kang, L. Wang, H. Dong, C. Wang, Z. Xiong, W. Zhao, C. Jia, J. Lin, W. Zhang, W. Yuan, M. Zhong, H. Du, X. Bai, Rictor/mTORC2 pathway in oocytes regulates folliculogenesis, and its inactivation causes premature ovarian failure, J. Biol. Chem. 290 (2015) 6387-6396.

[11] X. Hu, J.A. Flaws, I.G. Sipes, P.B. Hoyer, Activation of mitogen-activated protein kinases and AP-1 transcription factor in ovotoxicity induced by 4vinylcyclohexene diepoxide in rats, Biol. Reprod. 67 (2002) 718-724.

[12] Y. Takai, J. Canning, G.I. Perez, J.K. Pru, J.J. Schlezinger, D.H. Sherr, R.N. Kolesnick, J. Yuan, R.A. Flavell, S.J. Korsmeyer, J.L. Tilly, Bax, caspase-2, and caspase-3 are required for ovarian follicle loss caused by 4-vinylcyclohexene diepoxide exposure of female mice in vivo, Endocrinology 144 (2003) 69-74.

[13] J.I. Acosta, L. MayeR, J.S. Talboom, C.W. Tsang, C.J. Smith, C.K. Enders, H.A Bimonte-Nelson, Transitional versus surgical menopause in a rodent model: etiology of ovarian hormone loss impacts memory and the acetylcholine system, Endocrinology 150 (2009) 4248-4259.

[14] L.E. Wright, J.B. Frye, A.L. Lukefahr, S.L. Marion, P.B. Hoyer, D.G. Besselsen, J.L. Funk, 4-Vinylcyclohexene diepoxide (VCD) inhibits mammary epithelial differentiation and induces fibroadenoma formation in female Sprague Dawley rats, Reprod. Toxicol. 32 (2011) 26-32.

[15] F.M. Reis, N. Pestana-Oliveira, C.M. Leite, F.B. Lima, M.L. Brandão, F.G. Graeff, C. M. Del-Bem, J.A. Anselmo-Franci, Hormonal changes and increased anxietylike behavior in a perimenopause-animal model induced by 4vinylcyclohexene diepoxide (VCD) in female rats, Psychoneuroendocrinology 49 (2014) 130-140.

[16] M. Keck, M.J. Romero-Aleshire, Q. Cai, P.B. Hoyer, H.L. Brooks, Hormonal status affects the progression of STZ-induced diabetes and diabetic renal damage in the VCD mouse model of model of menopause model of menopause, Am. J. Physiol. Ren. Physiol. 293 (2007) F193-F199.

[17] M.J. Romero-Aleshire, M.K. Diamond-Stanic, A.H. Hasty, P.B. Hoyer, H.L. Brooks Loss of ovarian function in the VCD mouse-model of menopause leads to insulin resistance and a rapid progression into the metabolic syndrome, Am. J. Physiol. Regul. Integr. Comp. Physiol. 297 (2009) R587-R592.

[18] D.P. Pollow Jr., M.J. Romero-Aleshire, J.N. Sanchez, J.P. Konhilas, H.L. Brooks, ANGII-induced hypertension in the VCD mouse model of menopause is prevented by estrogen replacement during perimenopause, Am. J. Physiol. Regul. Integr. Comp. Physiol. 309 (2015) R1546-R1552.

[19] F. Mauvais-Jarvis, D.J. Clegg, A.L. Hevener, The role of estrogens in control of energy balance and glucose homeostasis, Endocr. Rev. 34 (2013) 309-338. 
[20] A. Rafacho, A.C. Boschero, H. Ortsäter, Functional and molecular aspects of glucocorticoids in the endocrine pancreas and glucose homeostasis, in: S. Magdeldin (Ed.), State of the Art of Therapeutic Endocrinology, InTech, Rijeka, 2012, pp. 121-152.

[21] A. Rafacho, H. Ortsäter, A. Nadal, I. Quesada, Glucocorticoid treatment and endocrine pancreas function: implications for glucose homeostasis, insulin resistance and diabetes, J. Endocrinol. 223 (2014) R49-R62.

[22] R.M. de Guia, A.J. Rose, S. Herzig, Glucocorticoid hormones and energy homeostasis, Horm. Mol. Biol. Clin. Investig. 19 (2014) 117-128.

[23] A. Rafacho, V.A. Giozzet, A.C. Boschero, J.R. Bosqueiro, Functional alterations in endocrine pancreas of rats with different degrees of dexamethasone-induced insulin resistance, Pancreas 36 (2008) 284-293.

[24] A. Rafacho, J.L. Abrantes, D.L. Ribeiro, F.M. Paula, M.E. Pinto, A.C. Boschero, J.R Bosqueiro, Morphofunctional alterations in endocrine pancreas of short- and long-term dexamethasone-treated rats, Horm. Metab. Res. 43 (2011) 275-281.

[25] A. Rafacho, L.M. Gonçalves-Neto, J.C. Santos-Silva, P. Alonso-Magdalena, B. Merino, S.R. Taboga, E.M. Carneiro, A.C. Boschero, A. Nadal, I. Quesada, Pancreatic alpha-cell dysfunction contributes to the disruption of glucose homeostasis and compensatory insulin hypersecretion in glucocorticoidtreated rats, PLoS One 9 (2014) e93531.

[26] K.A. Roth, R.J. Katz, Stress, behavioral arousal, and open field activity: a reexamination of emotionality in the rat, Neurosci. Biobehav. Rev. 3 (1979) 247-263.

[27] M. Antunes, G. Biala, The novel object recognition memory: neurobiology, test procedure and its modifications, Cogn. Process. 13 (2012) 93-110.

[28] L.P. Mayer, P.J. Devine, C.A. Dyer, P.B. Hoyer, The follicle-deplete mouse ovary produces androgen, Biol. Reprod. 71 (2004) 130-138.

[29] J.C. Lohff, P.J. Christian, S.L. Marion, A. Arrandale, P.B. Hoyer, Characterization of cyclicity and hormonal profile with impending ovarian failure in a novel chemical-induced mouse model of perimenopause, Comp. Med. 55 (2005) 523-527.

[30] V.A. Giozzet, A. Rafacho, A.C. Boschero, E.M. Carneiro, J.R. Bosqueiro, Dexamethasone treatment in vivo counteracts the functional pancreatic islet alterations caused by malnourishment in rats, Metabolism 57 (2008)617624.

[31] C. dos Santos, F.B. Ferreira, L.M. Gonçalves-Neto, S.R. Taboga, A.C. Boschero, A. Rafacho, Age- and gender-related changes in glucose homeostasis in glucocorticoid-treated rats, Can. J. Physiol. Pharmacol. 92 (2014) 867-878.

[32] E.A. Nunes, L.M. Gonçalves-Neto, F.B. Ferreira, C. dos Santos, L.C. Fernandes, A C. Boschero, P.C. Calder, A. Rafacho, Glucose intolerance induced by glucocorticoid excess is further impaired by co-administration with $\beta$-hydroxy- $\beta$-methylbutyrate in rats, Appl. Physiol. Nutr. Metab. 38 (2013) 1137-1146.

[33] L.M. Gonçalves-Neto, F.B. Ferreira, L. Souza, C. dos Santos, A.C. Boschero, V.A. Facundo, A.R. Santos, E.A. Nunes, A. Rafacho, Disruption of glucose tolerance caused by glucocorticoid excess in rats is partially prevented, but not attenuated, by arjunolic acid, Indian J. Exp. Biol. 52 (2014) 972-982.

[34] K. Motta, A.M. Barbosa, F. Bobinski, A.C. Boschero, A. Rafacho, JNK and IKK $\beta$ phosphorylation is reduced by glucocorticoids in adipose tissue from insulinresistant rats, J. Steroid Biochem. Mol. Biol. 145 (2015) 1-12.

[35] L.L. Luo, J. Huang, Y.C. Fu, J.J. Xu, Y.S. Qian, Effects of tea polyphenols on ovarian development in rats, J. Endocrinol. Investig. 31 (2008) 1110-1118.

[36] C.C. Juliani, E.C. Silva-Zacarin, D.C. Santos, P.A. Boer, Effects of atrazine on female Wistar rats: morphological alterations in ovarian follicles and immunocytochemical labeling of $90 \mathrm{kDa}$ heat shock protein, Micron 39 (2008) 607-616.

[37] P. Ge, N. Xing, Y. Ren, L. Zhu, D. Han, H. Kuang, J. Li, Preventive effect of American ginseng against premature ovarian failure in a rat model, Drug Dev. Res. 75 (2014) 521-528.

[38] L. Zhu, J. Li, N. Xing, D. Han, H. Kuang, P. Ge, American ginseng regulates gene expression to protect against premature ovarian failure in rats, Biomed. Res. Int. 2015 (2015) 767124.
[39] F.S. Muhammad, A.K. Goode, N.D. Kock, E.A. Arifin, J.M. Cline, M.R. Adams, P.B. Hoyer, P.J. Christian, S. Isom, J.R. Kaplan, S.E. Appt, Effects of 4 vinylcyclohexene diepoxide on peripubertal and adult Sprague-Dawley rats: ovarian, clinical, and pathologic outcomes, Comp. Med. 59 (2009) 46-59.

[40] Z. Ben-Rafael, C.A. Benadiva, C.J. García, G.L. Flickinger, Cortisol stimulation of estradiol and progesterone secretion by human granulosa cells is independent of follicle-stimulating hormone effects, Fertil. Steril. 49 (1988) 813-816.

[41] D. Bider, C. Pariente, J. Dor, M. Zolti, S. Mashiach, Z. Ben-Rafael, Aromatase activity of human granulosa cells in patients with polycystic ovaries treated with dexamethasone, Fertil. Steril. 54 (1990) 597-600.

[42] P. Chimin, S. Farias Tda, F.L. Torres-Leal, A. Bolsoni-Lopes, A.B. Campaña, S. Andreotti, F.B. Lima, Chronic glucocorticoid treatment enhances lipogenic activity in visceral adipocytes of male Wistar rats, Acta Physiol. (Oxf.) 211 (2014) 409-420.

[43] A.O. Protzek, J.M. Costa-Júnior, L.F. Rezende, G.J. Santos, T.G. Araújo, J.F. Vettorazzi, F. Ortis, E.M. Carneiro, A. Rafacho, A.C. Boschero, Augmented $\beta$-cell function and mass in glucocorticoid-treated rodents are associated with increased islet Ir- $\beta / A K T / m T O R$ and decreased AMPK/ACC and AS160 signaling, Int. J. Endocrinol. 2014 (2014) 983453.

[44] R.L. Thunhorst, T.G. Beltz, A.K. Johnson, Glucocorticoids increase salt appetite by promoting water and sodium excretion, Am. J. Physiol. Regul. Integr. Comp. Physiol. 293 (2007) R1444-R1451.

[45] S.B. Choi, J.S. Jang, S. Park, Estrogen and exercise may enhance beta-cell function and mass via insulin receptor substrate 2 induction in ovariectomized diabetic rats, Endocrinology 146 (2005) 4786-4794.

[46] J. Burén, Y.C. Lai, M. Lundgren, J.W. Eriksson, J. Jensen, Insulin action and signalling in fat and muscle from dexamethasone-treated rats, Arch. Biochem. Biophys. 474 (2008) 91-101.

[47] A.O. Protzek, L.F. Rezende, J.M. Costa-Júnior, S.M. Ferreira, A.P. Cappelli, F.M. de Paula, J.C. de Souza, M.A. Kurauti, E.M. Carneiro, A. Rafacho, A.C. Boschero, Hyperinsulinemia caused by dexamethasone treatment is associated with reduced insulin clearance and lower hepatic activity of insulin-degrading enzyme, J. Steroid Biochem. Mol. Biol. 55 (2016) 1-8.

[48] C.L. Shults, E. Pinceti, Y.S. Rao, T.R. Pak, Aging and loss of circulating 17estradiol alters the alternative splicing of ER in the female rat brain, Endocrinology 156 (2015) 4187-4199.

[49] J.A. Kobashigawa, B.L. Kasiske, Hyperlipidemia in solid organ transplantation, Transplantation 63 (1997) 331-338.

[50] A.M. Barbosa, P.C. Francisco, K. Motta, T.R. Chagas, C. dos Santos, A. Rafacho, E. A. Nunes, Fish oil supplementation attenuates changes in plasma lipids caused by dexamethasone treatment in rats, Appl. Physiol. Nutr. Metab. 41 (2016) 382-390.

[51] M. Franco-Colin, A.M. Tellez-Lopez, L. Quevedo-Corona, R. Racotta, Effects of long-term high-sucrose and dexamethasone on fat depots, liver fat, and lipid fuel fluxes through the retroperitoneal adipose tissue and splanchnic area in rats, Metabolism 49 (2000) 1289-1294.

[52] B.G. Slavin, J.M. Ong, P.A. Kern, Hormonal regultation of hormonesensitive lipase activity and mRNA levels in isolated rat adipocytes, J. Lipid Res. 35 (1994) 1535-1541.

[53] G.M. Kowalski, C.R. Bruce, The regulation of glucose metabolism: implications and considerations for the assessment of glucose homeostasis in rodents, Am. J. Physiol. Endocrinol. Metab. 307 (2014) E859-E871.

[54] S. Soriano, A.B. Ropero, P. Alonso-Magdalena, C. Ripoll, I. Quesada, B. Gassner M. Kuhn, J.A. Gustafsson, A. Nadal, Rapid regulation of K(ATP) channel activity by 17 -estradiol in pancreatic-cells involves the estrogen receptorand the atrial natriuretic peptide receptor, Mol. Endocrinol. 23 (2009) 1973-1982.

[55] Y. Yuchi, Y. Cai, B. Legein, S. De Groef, G. Leuckx, V. Coppens, E. Van Overmeire, W. Staels, N. De Leu, G. Martens, J.A. Van Ginderachter, H. Heimberg, M. Van de Casteele, Estrogen receptor $\alpha$ regulates $\beta$-cell formation during pancreas development and following injury, Diabetes 64 (2015) 3218-3228. 